\title{
Evaluation of the College English Flipped Classroom Teaching Model Based on Data Mining Algorithms
}

\author{
Jiangshui Xiang \\ Baotou Railway Vocational \& Technical College, Baotou 014060, China \\ Correspondence should be addressed to Jiangshui Xiang; 20141052@stu.nun.edu.cn
}

Received 24 August 2021; Accepted 30 September 2021; Published 26 October 2021

Academic Editor: Fazlullah Khan

Copyright (C) 2021 Jiangshui Xiang. This is an open access article distributed under the Creative Commons Attribution License, which permits unrestricted use, distribution, and reproduction in any medium, provided the original work is properly cited.

\begin{abstract}
Aiming at the problem of the inability to classify data due to the excessive amount of teaching resources, which leads to the college English flipped classroom teaching model's low resource sharing rate and the poor accuracy of score statistical analysis, a university-based data mining algorithm is designed. Research on the evaluation of english flipped classroom teaching model is conducted, the strategy of applying the flipped classroom in college English teaching is analyzed, the characteristics and advantages of this model are explored, the data mining algorithm to practical teaching is applied, and the decision tree C4.5 classification technology is used to achieve accurate classification of massive student test scores. The classification technology selects classification attributes based on the information gain rate. It uses the postpruning method to process data to improve the accuracy of data classification. Finally, the statistical analysis results of the business logic layer are transmitted to the user through the browser application layer using the WEB server. The experimental results show that using this article's evaluation method, the college English flipped classroom teaching model can achieve a high resource sharing rate, high accuracy of performance statistics analysis, and a good teaching effect.
\end{abstract}

\section{Introduction}

The flipped classroom, as a product of the integration of teaching reform and the information age, refers to a specific inversion of the theoretical guidance of the classroom and the consolidation of the after-school knowledge based on the original subject teaching mode. Specifically, students use online video as a carrier to conduct online theoretical learning and use corresponding exercises to consolidate and deepen their theoretical knowledge [1]. At the same time, teachers answer the questions raised by students online to help them achieve the perfection of the theoretical system and the improvement of subject literacy. The reason for the introduction and application of the flipped classroom model in college English teaching is largely due to the studentcentered teaching concept that it highlights. In this process, students can break the limitations of time and space and choose the content and time of learning in a targeted manner according to their own hobbies, learning characteristics, and problems, which greatly motivates them to participate in subject learning positivity and subjective initiative. However, under the shackles of the original one-way theoretical teaching model, students often passively accept the teacher's theoretical transmission and lack deeper thinking and practice. As a result, their subject quality, independent learning ability, and innovative and creative consciousness are difficult to achieve the ideal state. The effective introduction and application of flipped classrooms in the process of college English teaching can not only greatly stimulate the enthusiasm and subjective initiative of students to participate in subject learning, but also help cultivate their independent learning ability, teamwork ability, and innovation in a subtle way. It develops creative ability to better adapt to the quality needs of the development of the times for talents [2]. All in all, in this teaching process, teachers gradually transition from the original leader to the role of a guide, which is very helpful for cultivating students' independent learning ability and innovative and creative consciousness. The traditional college English teaching quality evaluation system is subjective and one-sided. For example, suppose the 
teaching administrator weighs the student-teachers evaluation scores as the teacher's evaluation result, it will lead to the irrationality of the evaluation results, which may make the evaluation results unreasonable. As a result, managers make decision-making mistakes. Therefore, establishing a scientific evaluation system and its practical use is of great significance to the management of college English teaching [3]. The flipped teaching in classroom is usually described as activities being conventionally carried out by students present outside the class (i.e., they practice the problem towards solution), afterwards they shift back to the classroom session; on the contrary, the conventional classroom approach used (i.e., exposition and transmission of information by the teaching method) is executed outside the class and normally before the class. The data mining method in the education sector consists of statistics, concept visualization, applying classification, creating clustering with associative based analysis, applying anomaly identification, and involves text-based mining [4]. A previous study showed that [5] the education sector applies the data mining approach to determine the time spent by students in viewing and using learning materials to classify behaviors of viewing.

The study in [6] proposes to study the characteristics and laws of college English education based on cognitive process simulation. First, it explains the basic theories of metacognition and the advantages and methods used in English teaching. Then, a mathematical model of college oral English teaching and how to improve the oral pronunciation of oral learners through quantitative and effective evaluation was established. Afterwards, targeted information evaluation results are given, and the algorithm is optimized and improved. Finally, using computer-assisted technology and metacognitive methods, the effects of oral English teaching were simulated and tested. The study in [7] proposed to use a systematic evaluation method to compare and analyze the teaching effects of SPOC flipped classroom and traditional teaching and conduct statistical analysis of its effect value through meta-analysis methods, so as to increase the sample size and draw more scientific conclusions. The results show that the test scores, knowledge comprehension ability, knowledge application ability, self-learning ability, selfmanagement ability, and learning motivation of SPOC flipped classroom are higher than those of the traditional classroom. Characterizations of the flipped-based teaching in classroom are discussed in many ways. Few of them focus on the usage of digital technology $[7,8]$, few of them target social media [9], and few discuss the significance of applying a certain pedagogical way, like mastery-based learning [10] or cooperative learning method [11]. Though there are substantial dissimilarity, it is possible to distil some common core features that are present in virtually all the definitions. On this basis, this paper proposes a research on the evaluation of college English flipped classroom teaching model based on data mining algorithms.

The rest of the paper is organized as follows. Section 2 gives an overview on college English flipped classrooms teaching model literature, Section 3 discusses the evaluation of teaching modes, Section 4 discusses experimental analysis, and Section 5 presents conclusion.

\section{College English Flipped Classroom Teaching Mode}

2.1. Research on the Strategy of Applying Flipped Classroom in College English Teaching. The flipped classroom, as a product of the integration of teaching reform and the information age, refers to a specific inversion of the theoretical guidance of the classroom and the consolidation of after-school knowledge based on the original subject teaching mode. Specifically, students use online video as a carrier to conduct online theoretical learning and use corresponding exercises to consolidate and deepen their theoretical knowledge. At the same time, teachers answer the questions raised by students online to help them achieve the perfection of the academic system and the improvement of subject literacy. The reason for the introduction and application of the flipped classroom model in college English teaching is largely due to the studentcentered teaching concept that it highlights. In this process, students can break the limitations of time and space and choose the content and time of learning in a targeted manner according to their own hobbies, learning characteristics, and problems, which greatly motivates them to participate in subject learning positivity and subjective initiative. Under the shackles of the original one-way theoretical teaching model, students often passively accept the teacher's theoretical transmission, lacking deeper thinking and practice, so their own subject quality, independent learning ability, and innovative and creative consciousness are difficult to achieve ideal state. The practical introduction and application of flipped classrooms in the process of college English teaching can greatly stimulate the enthusiasm and subjective initiative of students to participate in subject learning and help cultivate their independent learning ability, teamwork ability, and innovation in a subtle way. Creative ability to better adapt to the quality needs of the development of the times for talents. In this teaching process, teachers gradually transition from the original leader to the role of guide, which is very helpful for cultivating students' independent learning ability and innovative and creative consciousness [6]. In order to allow students to make full use of class time, college English flipped classroom teaching enables students to readjust their time inside and outside the class, fully understand the content of the experiment before the class, put the consolidation of knowledge outside the class, and enable students to fully grasp the knowledge points in the course. Students arrange their time reasonably according to their own learning situation to maximize the time spent on teaching and learning. Teachers in class answer questions based on the English practice before the experimental class to prevent students from failing to answer questions in time. To better teach students by their aptitude, data mining algorithms are used to analyze and push different experimental questions through the feedback of 
students' exercises before class. Students solidify the knowledge they have learned after class, summarize the errors and solutions that occurred during the programming process in the experimental class, and write a personalized experimental report. Figure 1 is a comparison of teaching and learning activities. The comparison of teaching and learning activities is shown in Figure 1.

The application of college English flipped classroom teaching model mainly includes the following four points:

(i) Firmly grasping the main points of teaching

Compared with junior and senior high school English teaching, college English highlights the characteristics of complex content and more incredible difficulty. Therefore, in applying the flipped classroom model, the knowledge points involved in classroom teaching should be systematically divided. The integration of science provides a solid theoretical support for the production of videos, ensuring that the videos produced can fully cover the key points and difficulties involved in classroom theory teaching and lay a solid material foundation for students' independent learning. To achieve this goal, English teachers need to deeply explore the elements closely related to their teaching content in real life and rationally integrate them, scientifically analyze them, and use them efficiently to realize the integration of professional teaching content with daily life cases. Effective integration provides students with a more relaxed and lively learning method [7]. On this basis, according to the learning tasks and talent training goals of different units, problems can be set up on the network platform in a targeted manner. They can be regular problems that test students' theoretical mastery, or they can test students' innovation and creativity. The open question of ability helps them apply and test theoretical knowledge in the process of practice and realize the overall improvement in their own disciplinary quality and comprehensive quality. The integration of learning methods for junior and higher cadre schools is discussed [8].

(ii) Reasonable control of the video content

The production of instructional videos must rely on related scripts. Still, in the actual production process, the content and length of the video should be reasonably controlled to ensure the maximum educational value. Specifically, the video is the foundation for the creation of flipped classrooms. Therefore, in the process of selecting the content of video production, teachers must firmly grasp the learning foundation, cognitive ability, hobbies, and developmental needs of the group of college students to be targeted. The teaching content shoud be selected and arranged carefully, and should be presented in a livelier form. In this way, it can effectively attract the attention of the majority of students and enhance their enthusiasm and

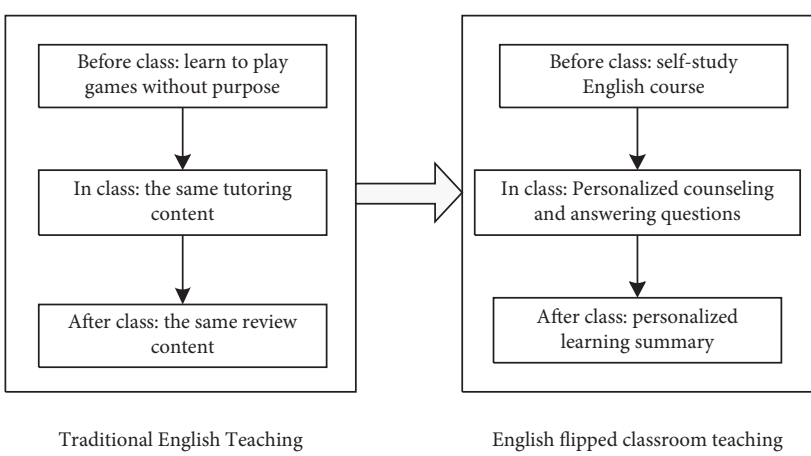

Figure 1: Comparison of teaching and learning activities.

subjective initiative to participate in the flipped classroom. As far as the production time of the video is concerned, the practice has proved that it is generally difficult for students to concentrate on one thing for a long time. Therefore, the video length should be controlled between four and six minutes to protect the efficiency and quality of independent learning of most students [8].

(iii) Effectively carrying out interactive tests

Compared with the traditional one-way instillation theory teaching model, the value of the flipped classroom is to greatly promote the interaction between teachers and students, so that they can more intuitively explain their various problems and doubts in the learning process, at the same time, get the necessary guidance from teachers. Therefore, in the actual teaching process, teachers should carry out targeted online interactive testing activities to test the learning effect of students by watching videos to arrange teaching content, set teaching progress, select teaching methods, and realize their teaching work To develop an effective fit with the diverse developmental needs of the majority of students. On this basis, the teacher can divide the whole class into several study groups in a homogeneous group arrangement and heterogeneous group arrangement within the group and guide the students to communicate and discuss in groups after watching the instructional video. In this process, students can learn about their learning problems in a timely manner, so that they can find out and fill vacancies in a more targeted manner and avoid the embarrassing situation of confusion.

(iv) Solving student problems in time

Compared with other teaching modes, the application of flipped classrooms significantly highlights the student's dominant position, so there are higher requirements for their independent learning ability, but this does not mean that they can be separated from the teacher's guidance. When applying flipped classrooms, teachers should promptly follow-up on different students' learning situations, comprehensively consider their problems and confusions in 
the learning process, and use a combination of online and offline methods to guide students scientifically and timely with Q\&A. However, based on the actual difficulty of relevant subjects in college English, teachers should preset a series of problems that students may have in the process of autonomous learning in advance when making videos, so as to deepen the key and difficult knowledge of this lesson and help students better in understanding relevant theories and avoid fear of difficulties. It should be noted that when answering students' questions in the learning process, teachers should gradually guide students to follow correct thinking and use the correct methods to solve the problems, so as to promote the overall improvement of their thinking ability and innovation level.

\subsection{Features and Advantages of the College English Flipped} Classroom Teaching Model. The college English flipped classroom teaching model reverses the process of knowledge transfer and knowledge internalization. This "disruptive innovation" teaching model has the following advantages:

(i) Optimized teaching resources

Traditional college English teaching resources are mainly textbooks, both the form and content are relatively simple. However, the rapid development of modern information technology has promoted the rapid integration of education and information, making it possible to share college English teaching resources on a network, thereby realizing the timely and diversified acquisition of teaching resources and channels. Under the traditional teaching model, teachers can only use the limited time in the classroom to allow students to learn and experience limited teaching resources. The flipped classroom teaching model makes teaching no longer limited by the time and space of the classroom, as long as the teacher can provide students with learning websites and teaching. With learning resources such as videos and the ways to obtain them, students can independently complete college English learning tasks. Diversified presentation and multichannel access to teaching resources are convenient and affordable and can meet the learning needs of students at the same time. It can enrich students' college English knowledge, improve their English proficiency, cultivate students' interest in English learning, expand students' English horizons, and so on, which are of great significance.

(ii) Dual teaching platform

Students learn English from elementary school and some even from kindergarten to university. Still, improving students' English knowledge and skills have always been in a "time-consuming and inefficient" state. An important reason for this phenomenon is the simplification of the English teaching platform. Traditional English teaching has only the English classroom as a teaching platform. If students leave the classroom, they will lose the guidance place for English learning, which is naturally not conducive to improving students' English proficiency. Under the flipped classroom model, in addition to the original English classroom teaching platform, college English teaching also has an online English teaching platform based on information terminal equipment and information technology. In particular, the use of online platforms has enabled college English teaching to take place by searching, creating, integrating, and uploading network resources, organizing online discussions and answering questions, designing online tests, and conducting online evaluations before classroom teaching started. The classroom is no longer a place for teachers to indoctrinate students with one-way knowledge, but a place for teachers and students or students and students to conduct dialogues and exchanges, "question and question," and explore knowledge together. The dual teaching platform can meet the needs of students' English learning to a greater extent and improve the effect of students' English course learning.

(iii) Independent and collaborative learning methods

The effective implementation of the flipped classroom depends on students' autonomous and collaborative learning. The flipped classroom teaching model has repositioned the role of students. Students' main body status has been constantly revealed, and they have become managers of learning. The teaching process largely depends on the learning state of students. College English flipped classroom is a classroom where students build knowledge in depth. Students are the protagonists of the classroom. If students do not complete the independent study of the course content before class, classroom teaching activities will not be possible; if there are no students actively participating in the flipped classroom learning activities and practices, the expected effect will be challenging to achieve. At the same time, flipped classroom teaching emphasizes mutual aid and collaborative learning between students. Mutual assistance and joint understanding demonstrate the new curriculum of the concept of "student-centered" teaching. With the mutual assistance and cooperation between students, students can guide each other, supervise each other, encourage each other, and evaluate each other in learning and practice, and finally complete the learning task and truly teach students according to their aptitude.

(iv) Individualized teaching methods

It is an important topic that has plagued the education circle for a long time to explore how to conduct personalized teaching according to differences among students. To overcome this problem, scholars and experts in the education circle tried to 
use hierarchical teaching, group teaching, and other methods, but ultimately failed to achieve the purpose of individualized teaching instruction. The number of teacher-centered students model is to achieve "student-centered "teacher-centred ha sizing that preclass students complete the learning tasks prescribed by teachers through online teaching resources according to their person, interest, and needs. The main task of teachers is the design of the online teaching platform, timely online guidance, and the creation of a good learning atmosphere. In the classroom, in addition to the necessary explanations and demonstrations according to the students' learning situation, the teachers give most of the time to the students, and the students use the cooperation and discussion between teachers and students, students and students, and evaluate their classmates and their learning. Furthermore, activities such as reflection further internalize and consolidate knowledge and skills [9].

The flipped classroom teaching model reverses the process of knowledge transfer and knowledge internalization. This "disruptive innovation" teaching model has the following advantages:

(i) Flipped classroom helps students solve the problem of time. The flipped classroom will present part of the knowledge in front of the students before the class, supplemented with appropriate guidance, so that students can learn anytime and anywhere. These learning materials solve the problems of the students in the classroom for some reasons and can also be based on their own. The situation grasps the learning process, so that students have greater autonomy in their own learning.

(ii) Flipped classroom increases teacher-student interaction and student-student interaction. The interaction between teachers and students is one of the important links in the teaching process, and it also has a great influence on the teaching effect. In the flipped classroom, teachers are required to organize a variety of classroom activities and promote the internalization of student knowledge through classroom activities. Compared with traditional teaching, teacher-student interaction and studentstudent interaction have been greatly increased.

(iii) Flipped classroom enhances students' creativity. In traditional classrooms, teachers practice "cracking duck teaching," paying more attention to language expression and mechanical memory, stifling students' creativity. Flipping the classroom attempts to release students and change this tradition.

(iv) Flipped classroom enables teachers to understand students better and achieve personalized learning. At present, social education is mainly based on group education. Teachers teach on the stage but do not go near the students. Students are the main body of learning, and the flipped classroom teaching model recognizes the differences in students, allowing students to control the learning process and achieve personalized learning. When personalized learning emerges, teachers have a deeper understanding of students.

\section{Evaluation of the Teaching Model Based on Data Mining Algorithm}

According to the students' learning situation, the use of data mining algorithms for analysis and personalized push of experimental tasks can more fully activate and release students' innovative thinking and significantly improve the effectiveness of college English teaching.

3.1. Overview of Decision Tree Algorithm. Cluster analysis, apriori algorithm, genetic algorithm, decision tree method, and other methods are all methods that can be applied to data mining. When evaluating the teaching mode, it is decided to choose the decision tree algorithm because it has the advantage of simple description. The algorithm can display decision-making attributes, have a higher classification accuracy, a smaller amount of calculation, faster classification speed, simple extraction of explicit rules, and other characteristics [10].

Data mining is a repetitive process, which can support decision-making or assist people in processing data, and can also guide calculators to process data. Therefore, data mining technology is a deeper data information analysis method in a sense. The use of data mining technology in evaluating and analyzing college English flipped classroom teaching model is significant. Compared with traditional evaluation and analysis methods, data mining technology can find variously hidden, relevant, and essential attributes from the college English flipped classroom teaching model's results and find the inevitable connections between them through further analysis. This advantage is beyond the reach of traditional methods. Data mining randomly divides the given data to be processed into two independent sets of the training set and test set. In addition, after the data mining process is combined with actual engineering practice, a detailed description should be provided. The report should be based on the specific technical process of data mining. For example, the college English flipped classroom teaching model evaluation system should include demand capture and analysis, design, specific implementation and testing, etc. First, the collected data information of the college English flipped classroom teaching model of students is gathered to form a data source of the college English flipped classroom teaching model information. These data structures require a standardized and unified data structure, and then the work of processing the operating data is completed so that the algorithm proceeds to the next stage. The algorithm requires a repeated index to find the best split, and then uses an appropriate pruning algorithm until the pruning generates the initial decision tree [11]. 
A simple tree is constructed, which is why the C4.5 algorithm is used. This is to improve the decision tree's attributes, choose the measurement's interpretability, and then make the corresponding pruning, delete the empty branches, and reduce the unused components to avoid overfitting. The C4.5 decision tree is set as the base classifier, and an ensemble model is designed based on the decision tree. The design steps of this ensemble model are shown in Figure 2.

As shown in Figure 2, the design steps of the integrated model based on the decision tree are as follows:

(i) Collecting student achievement data of college English flipped classroom teaching

(ii) Setting the collected data into the training set and test set

(iii) Establishing an integrated classifier through multiple base classifiers, and the data in the training set is imported into the integrated classifier to realize the evaluation of the teaching mode

3.2. Design of the Evaluation System Using Decision Tree Generation Algorithm. The decision tree generation algorithm mainly includes two parts: a spanning tree and a pruning tree. When the initial algorithm runs, all data are concentrated in the root node of the established decision tree. After that, the information is recursively shared; after the decision tree is generated, abnormal data need to be removed and noise data are deleted. Finally, when no attributes can be applied to split data, and all data in the same node belong to the same category, the decision tree split is completed, and the algorithm operation ends. According to the requirements of the college English flipped classroom teaching performance analysis system, the decision tree C4.5 algorithm is improved, and the same attribute set is established through the information gain ratio of different attributes, which is represented by $S$, and the attributes of different values are created to establish the decision tree branch, and the decision tree branch is used to divide college English flipped classroom teaching results. The improved decision tree C4.5 algorithm is given below.

3.2.1. Classification Attribute is Selected Based on the Information Gain Rate. The use of information gain rate to select college English flipped classroom teaching performance attributes, compared with the help of information gain to select college English flipped classroom teaching results, has a higher computational efficiency [12]. $F_{j}$ and $E=F_{1} * F_{2} * \cdots * F_{n}$ are used to denote the finite discrete symbol set and the finite vector space, respectively. The dimension of the finite vector space is $n$, and the example $e=\left\langle w_{1}, w_{2}, \ldots, w_{n}\right\rangle$ is the inner element of $E$ and $w_{j} \in F$. Let the two example sets in $E$ be represented by $Y_{E}$ and $N_{E}$, respectively; $y$ represents the size of the positive example set in the vector space, and $n$ represents the size of the negative example set in the vector space.

The same decision tree realizes the accurate judgment of the amount of information required by the sample set based on the correct classification. $y_{i}$ and $n_{i}$ are used to denote the

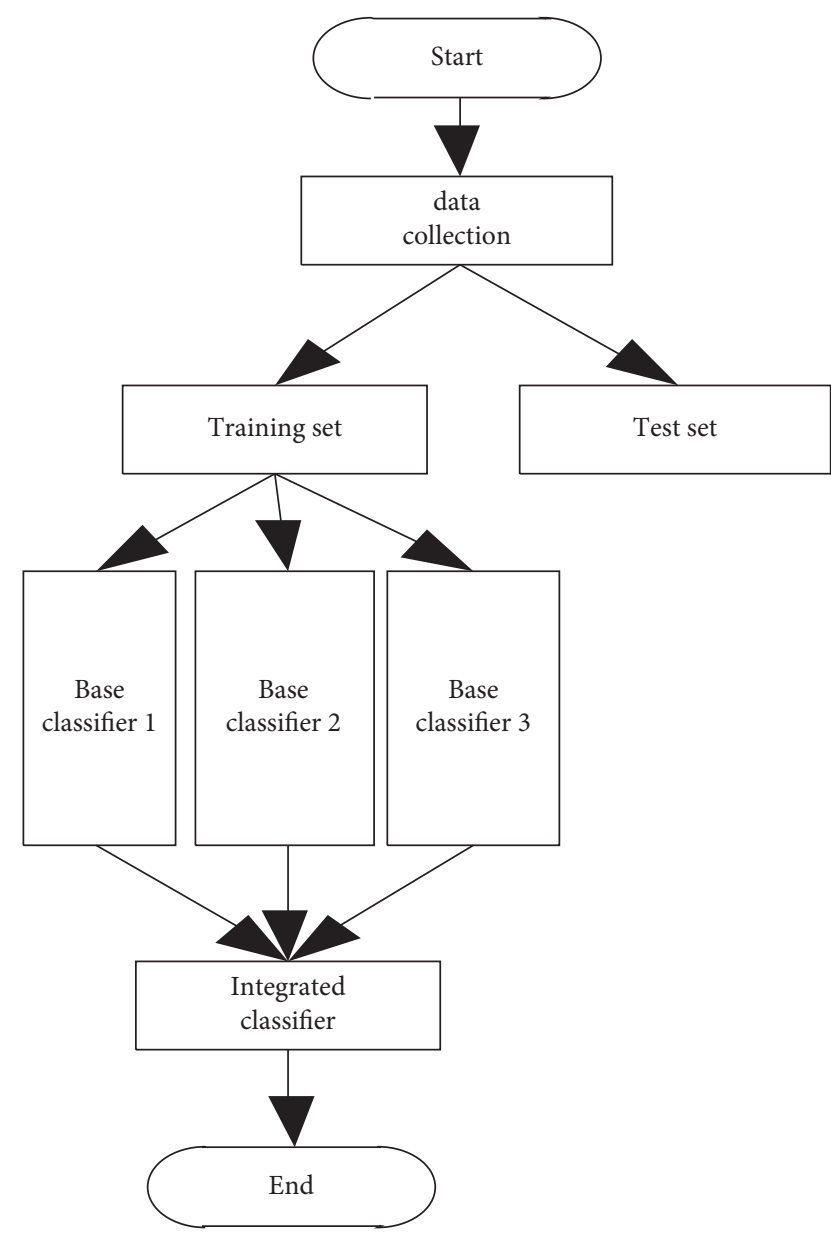

Figure 2: Schematic diagram of the design steps of the integrated model based on decision tree.

number of positive examples and the number of negative examples in vector space $E_{i}$, respectively, and the information required for vector space $E_{i}$ can be expressed as follows:

$$
I\left(y_{i}, n_{i}\right)=\frac{y_{i}}{y_{i}+n_{i}} \log _{2} \frac{y_{i}}{y_{i}+n_{i}}-\frac{n_{i}}{y_{i}+n_{i}} \log _{2} \frac{y_{i}}{y_{i}+n_{i}} .
$$

The expression of the information entropy of the root node with attribute $A$ is as follows:

$$
E(A)=\sum_{i=1}^{y} \frac{y_{i}+n_{i}}{y+n} I\left(y_{i}, n_{i}\right) .
$$

The above formula is simplified to get the formula as follows:

$$
E(A)=\frac{1}{(y+n) \ln (2)} \sum_{i=1}^{y}\left(-y_{i} \ln \frac{y_{i}+n_{i}}{y+n}\right)-n_{i} \ln \frac{n_{i}}{y+n} .
$$

In the training set, $1 /(y+n) \ln (2)$ is a constant value, and the function must conform to the following formula:

$$
E(A)=\sum_{i=1}^{y}\left(-y_{i} \ln \frac{y_{i}}{y_{i}+n_{i}}\right)-n_{i} \ln \frac{n_{i}}{y+n} .
$$


According to the principle of equivalent infinitesimal, using McLaughlin's formula and Taylor's formula to simplify the calculation of information entropy, the expression for the existence of $x$ minute is obtained as follows:

$$
\begin{gathered}
\ln \frac{n_{1}}{y_{1}+n_{1}}=\ln \left(1-\frac{y_{1}}{y_{1}+n_{1}}\right) \approx \frac{n_{1}}{y_{i}+n_{i}}, \\
\ln \frac{y_{i}}{y_{i}+n_{i}}=\ln \left(1-\frac{y_{i}}{y_{i}+n_{i}}\right) \approx \frac{n_{i}}{y_{i}+n_{i}} .
\end{gathered}
$$

Substituting the above formula, the expression can be obtained as follows:

$$
E(A)=\sum_{i=1}^{y}\left(-y_{i} \ln \frac{y_{i}}{y_{i}+n_{i}}\right)-n_{i} \ln \frac{n_{i}}{y_{i}+n_{i}} \approx \sum_{i=1}^{y} \frac{2 y_{i} n_{i}}{y_{i}+n_{i}} .
$$

After splitting the above formula, the formula can be obtained as follows:

$$
\begin{aligned}
\operatorname{SplitI}(A) & =-\frac{n_{i}}{y_{i}+n_{i}} \log _{2} \frac{y_{i}}{y_{i}+n_{i}}-\frac{y_{i}}{y_{i}+n_{i}} \log _{2} \frac{y_{i}}{y_{i}+n_{i}} \\
& \approx \sum_{i=1}^{y} \frac{2}{\ln 2} \frac{y_{i} n_{i}}{\left(y_{i}+n_{i}\right)^{2}} .
\end{aligned}
$$
follows:

The available information gain rate expression is as

$$
\operatorname{Gain}(A)-\operatorname{ratio}(A)=\frac{\operatorname{Gain}(A)}{\operatorname{spliti}(A)}=\frac{I(A)-E(A)}{\operatorname{spliti}(A)} .
$$

After simplifying the information entropy formula, a score formula $\sum_{i=1}^{y} 2 y_{i} n_{i} / y_{i}+n_{i}$ is obtained, and the information splitting formula is simplified and transformed into $\sum_{i=1}^{y} 2 / \ln 2 y_{i} n_{i} /\left(y_{i}+n_{i}\right)^{2}$. The amount of information is split and calculated according to the above formula, and the attribute with the largest information gain rate is set as the root node of the decision tree [13]. After the improvement of the decision tree classification algorithm, the four mixed operations are used to replace the logarithmic operation to improve the operation speed [14].

3.2.2. Postpruning Method. The error evaluation of the postpruning method in the decision tree classification technology is realized by using training samples, which can avoid overfitting of college English flipped classroom teaching score data, avoid the continuous growth of the decision tree, and determine the pruning situation after the error evaluation is completed. The formula for processing data using the postpruning method is as follows:

$$
c=\operatorname{Pr}\left[\frac{f-q}{\sqrt{q(1-q) / N}}>z\right] .
$$

In formula (9), $N$ and $q$, respectively, represent the number of instances and the true error rate; $f=E / N$ and $c$, respectively, represent the number of misclassifications and confidence when the number of instances is $N$, and $z$ represents the standard deviation. The normal distribution table is used according to the set confidence obtained in the confidence standard deviation result [15].

The above process is used to obtain the confidence interval of the true error rate $q$, and the nodal error rate $e$ using the upper limit of the confidence interval is estimated as follows:

$$
e=\frac{f+z^{2} / 2 N+Z \sqrt{f / N-f^{2} / N+z^{2} / 4 N^{2}}}{1+z^{2} / N} .
$$

The node error rate before and after pruning is estimated according to the above formula. The estimated node error rate result is used to judge whether the decision tree needs a pruning operation.

\subsection{Evaluation of the College English Flipped Classroom} Teaching Model. The learning English flipped classroom teaching model evaluation system is divided into management, teacher, student, data transmission, and mining modules. The structure of each functional module is shown in Figure 3.

3.3.1. Management Module. This module includes an evaluation project management module, student message management module, evaluation result ranking module, and course information maintenance module. The evaluation item management module can manage and maintain classroom teaching quality evaluation items and adjust the number of evaluation items or the content of the evaluation items as needed; the student message management module can manage student messages, shielding personal attacks on teachers or other illegal content. The evaluation result ranking module can be ranked according to the teacher's class or the teacher's scoring [16, 17]; the course information maintenance module can classify courses, each type, of course, can set different evaluation items, set up courses that do not need to be evaluated, or classrooms taught by multiple teachers are set up to make student evaluations more targeted.

3.3.2. Teacher Module. This module includes an evaluation result query module, a student message reply module, and a custom evaluation project management module [18-20]. The evaluation result query module can display the student's evaluation results intuitively in a table. The student message reply module can reply to students' opinions or suggestions and respond to a particular student or class. Leave a message. The custom evaluation item management module allows teachers to define up to 4 custom evaluation items for the classroom.

3.3.3. Student Module. This module includes an overall impression evaluation module, detailed evaluation module by item, text message evaluation module, and evaluation result query module. The general impression evaluation module is the overall evaluation of the teacher's classroom 


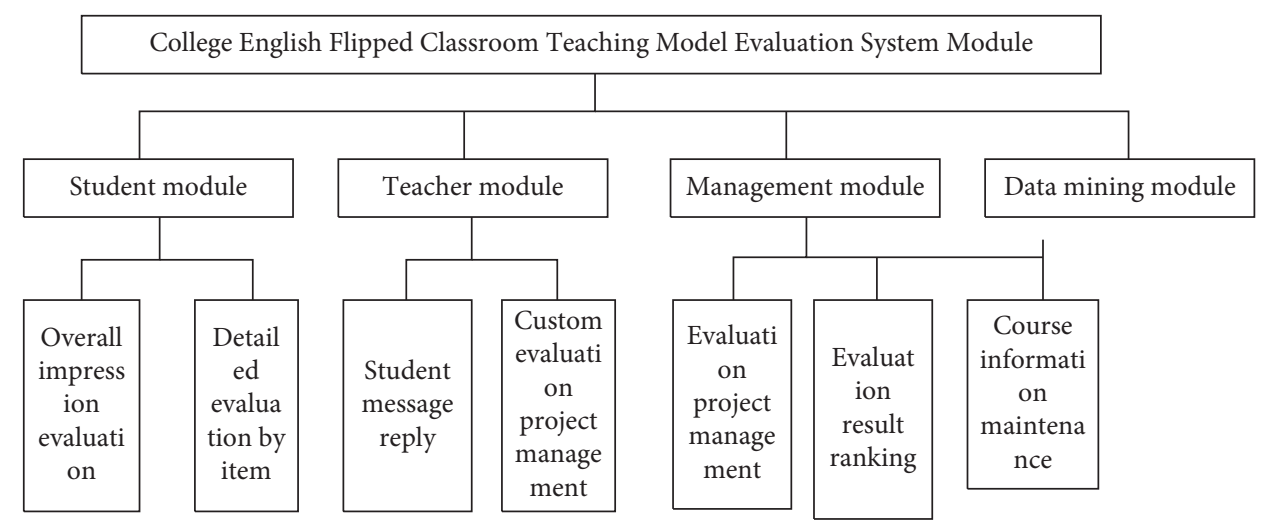

Figure 3: The evaluation system module of the college English flipped classroom teaching model.

TABLE 1: Comparison of experimental data of the resource sharing rate.

\begin{tabular}{lccc}
\hline \multirow{2}{*}{ The amount of shared teaching resources $(\mathrm{MB})$} & \multicolumn{3}{c}{ Resource sharing rate (kbps) } \\
& Evaluation method of this paper & Literature [4] method & Literature [5] method \\
\hline 2000 & 4256.2 & 347.10 & 369.30 \\
2200 & 435.4 & 312.58 & 356.30 \\
2400 & 441.6 & 365.20 & 336.30 \\
2600 & 435.8 & 362.01 & 325.30 \\
2800 & 434.6 & 355.63 & 344.30 \\
3200 & 452.4 & 339.63 & 352.01 \\
3400 & 434.5 & 345.30 & 33.20 \\
3600 & 441.3 & 301.22 & 33.20 \\
4000 & 439.4 & 356.30 & 361.04 \\
\hline
\end{tabular}

teaching. Before the students check the results of a particular course for the first time, they will evaluate the overall teaching quality of the classroom and the teacher and give a comprehensive evaluation grade and score. The detailed evaluation module by item is a quantitative evaluation of teachers' classroom teaching indicators. Students have two opportunities for a detailed evaluation of things in the system, both of which are voluntary evaluations, respectively, during the course teaching process and after the results are announced. The text message evaluation module is the overall impression evaluation; in addition to the important supplementary part of the detailed evaluation of items, students can express their true feelings about the course by leaving a message, and teachers can also know the student's learning status at any time. The evaluation result query module can evaluate the teacher's evaluation of the course selected by the student. The results are displayed intuitively in the form of a table.

3.3.4. Data Mining Module. This module is used by teaching administrators, including two parts: the server background data processing and the client foreground data display. The function of the data processing part is to perform data mining processing on the server-side according to the data model selected by the user and related parameters. The front-end data display part of the client's process is to visually display the data mining results to users in the form of tables or graphs.

\section{Experimental Analysis}

An English major in a university is selected as the system test analyst, and the test score of the English major is selected as the experimental data analysis object. The total score of the test paper is 100 points, and the pass score is 60 points. The system test object includes 300 graduate students.

In the range of shared college English teaching resources of $2000 \mathrm{MB}-4000 \mathrm{MB}$, the experimental data of the resource sharing rate comparison of different methods are shown in Table 1.

According to the experimental data of resource sharing rate comparison in Table 1, it can be seen that in the range of $2000 \mathrm{MB}-4000 \mathrm{MB}$ of the shared college English teaching resources, the resource sharing rate of the method in this paper is higher than those of the comparison methods. It can be seen that under different amounts of teaching resources, the method in this paper has a higher sharing rate of teaching resources, which can better realize the sharing of teaching and learning resources.

This system is used to statistically analyze the test scores of 300 graduate students and calculate the distribution of test scores of students of different majors based on the score segment. The statistical results are shown in Figure 4. 


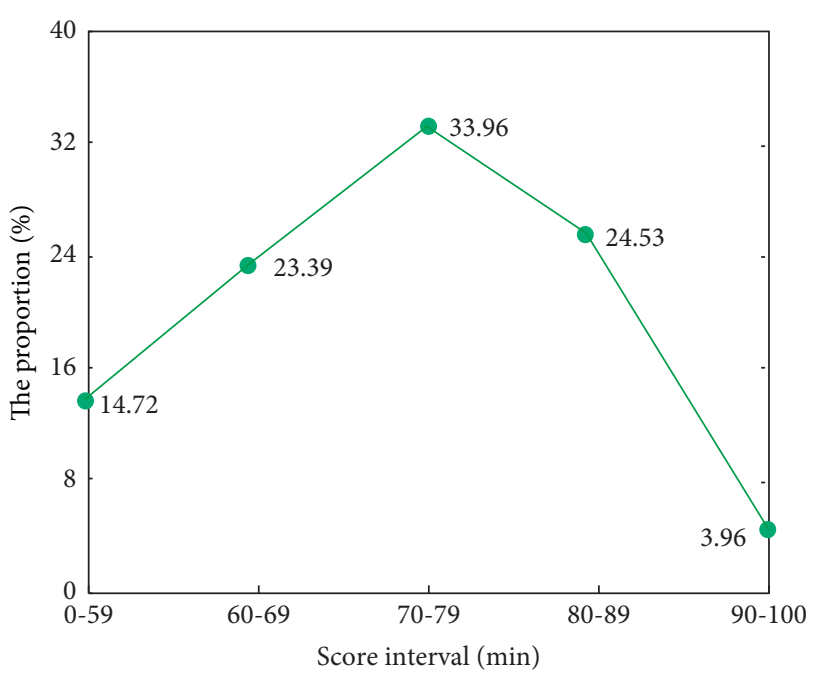

FIGURE 4: Scored segment statistical results.

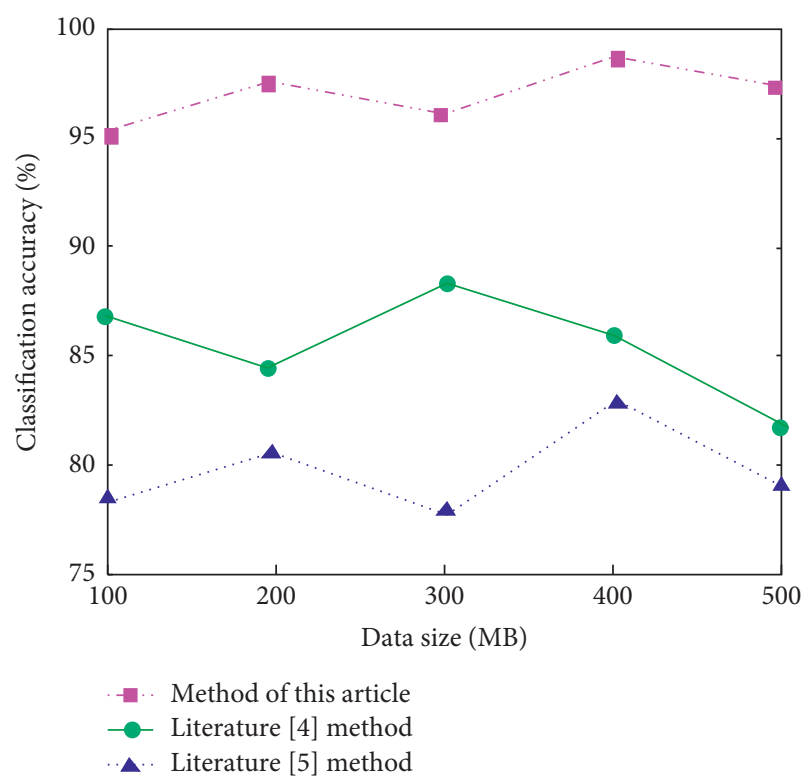

Figure 5: Classification accuracy.

It can be seen from the statistical results in Figure 4 that the method in this paper can effectively calculate the distribution of student performance based on the distribution of different scores. Teachers and school administrators can obtain intuitive results of the distribution of scores based on the statistics of student performance, which is helpful to formulate professional courses based on student performance. Therefore, the plan is highly applicable. The robustness refers to the ability of the evaluation method to classify data in the presence of data defects and noise. In order to verify the processing effect of the designed evaluation method on data of different scales, when the noise level is $30 \mathrm{~dB}$ for different data scales, the comparison results of the classification accuracy of the method in this paper are shown in Figure 5.
It can be seen from the experimental results in Figure 5 that the method used in this paper evaluates the college English flipped classroom teaching model, analyzes and counts students' test scores, and has high classification accuracy when different noises are added. The evaluation method in this article selects decision tree classification technology to classify the test scores of many students. According to the needs of users, different ways can be used to analyze the scores statistically. The statistical analysis of scores is highly accurate and robust. The evaluation method of this article can be applied in the actual evaluation of college English flipped classroom teaching model.

\section{Conclusion}

This research proposes an evaluation system for flipped classroom teaching models in colleges and universities to comprehensively master students, teaching content, teaching, and other tasks. The four elements of the learning environment are the teacher, student, learning material, and supporting environment dimensions as the first-level indicators. Into the analysis of the requirements or standards of each size in the flipped classroom implementation, using data mining algorithms to analyze the student's learning data, the student's interaction with the teacher in the classroom is higher and a good teaching effect is achieved. Furthermore, the actual application results show that the resource sharing rate of the college English flipped classroom teaching model obtained under this evaluation method is high, and the statistical score analysis is more accurate. Therefore, it is helpful to formulate professional curriculum plans based on student scores and is highly applicable.

\section{Data Availability}

The data used to support the findings of this study are available from the corresponding author upon request.

\section{Conflicts of Interest}

The author declares that he has no conflicts of interest.

\section{References}

[1] E. Humrickhouse, "Flipped classroom pedagogy in an online learning environment: a self-regulated introduction to information literacy threshold concepts," The Journal of Academic Librarianship, vol. 47, no. 2, Article ID 102327, 2021.

[2] Q. Jian, "Effects of digital flipped classroom teaching method integrated cooperative learning model on learning motivation and outcome," The Electronic Library, vol. 37, no. 5, pp. 842-859, 2019.

[3] Y. Xu, Y. Chu, F. Jiang, Y. Guo, and D. Gong, "SVMs classification based two-side cross domain collaborative filtering by inferring intrinsic user and item features," KnowledgeBased Systems, vol. 141, pp. 80-91, 2018.

[4] X. Xia and J. Yan, "Construction of music teaching evaluation model based on weighted naïve bayes," Scientific Programming, vol. 2021, Article ID 7196197, 9 pages, 2021. 
[5] Y. Xu, J. Yang, and Z. Xie, "Training SVMs on a bound vectors set based on Fisher projection," Frontiers of Computer Science, vol. 8, no. 5, pp. 793-806, 2014.

[6] H. Haghighi, M. Jafarigohar, H. Khoshsima, and F. Vahdany, "Impact of flipped classroom on EFL learners' appropriate use of refusal: achievement, participation, perception," Computer Assisted Language Learning, vol. 32, no. 1-4, pp. 261-293, 2019.

[7] L. R. Murillo-Zamorano, J. L. Sanchez, and A. L. GodoyCaballero, "How the flipped classroom affects knowledge, skills, and engagement in higher education: effects on students' satisfaction," Computers \& Education, vol. 141, no. Nov, pp. 103608.1-103608.18, 2019.

[8] P. Strelan, A. Osborn, and E. Palmer, "The flipped classroom: a meta-analysis of effects on student performance across disciplines and education levels," Educational Research Review, vol. 30, Article ID 100314, 2020.

[9] I. T. Awidi and M. Paynter, "The impact of a flipped classroom approach on student learning experience," Computers \& Education, vol. 128, no. 1, pp. 269-283, 2019.

[10] X. Yu, D. Zhan, L. Liu, H. Lv, L. Xu, and J. Du, “A privacypreserving cross-domain healthcare wearables recommendation algorithm based on domain-dependent and domainindependent feature fusion," IEEE Journal of Biomedical and Health Informatics, no. 1, , 2021.

[11] A. A. Yahya and A. Osman, "A data-mining-based approach to informed decision-making in engineering education," Computer Applications in Engineering Education, vol. 27, no. 6, pp. 1402-1418, 2019.

[12] H.-M. Liu, "Simulation of adaptive data mining method in hybrid storage video database," Computer Simulation, vol. 36, no. 6, pp. 259-262, 2019.

[13] J. Tinoco, M. D. Granrut, D. Dias, T. Miranda, and S. Alexandre-Gilles, "Piezometric level prediction based on data mining techniques," Neural Computing \& Applications, vol. 32, no. 1, pp. 4009-4024, 2020.

[14] L. Liu, "Research on IT English flipped classroom teaching model based on SPOC," Scientific Programming, vol. 2021, no. 5, 9 pages, Article ID 7273981, 2021.

[15] H. Chang, "College English flipped classroom teaching model based on big data and deep neural networks," Scientific Programming, vol. 2021, Article ID 9918433, 10 pages, 2021.

[16] Y. Xu, Q. Peng, L. Xu, F. Jiang, J. Du, and D. Gong, "A selective ensemble learning based two-sided cross-domain collaborative filtering algorithm," Information Processing \& Management, vol. 58, Article ID 102691, 2021.

[17] Y.-S. Su, C.-F. Ni, W.-C. Li, I.-H. Lee, and C.-P. Lin, “Applying deep learning algorithms to enhance simulations of large-scale groundwater flow in IoTs," Applied Soft Computing, vol. 92, Article ID 106298, 2020.

[18] H. Du, "An english network teaching method supported by artificial intelligence technology and WBIETS system," Scientific Programming, vol. 2021, Article ID 8783899, 9 pages, 2021.

[19] S. Yang, "Construction of video courses of physical education and health education in colleges and universities under the MOOC platform," Mobile Information Systems, vol. 2021, Article ID 9925838, 8 pages, 2021.

[20] Z. He, "English grammar error detection using recurrent neural networks," Scientific Programming, vol. 2021, Article ID 7058723, 8 pages, 2021. 